Article

\title{
Thermal Analysis of the Driving Component Based on the Thermal Network Method in a Lunar Drilling System and Experimental Verification
}

\author{
Dewei Tang *, Hong Xiao *, Fanrui Kong, Zongquan Deng, Shengyuan Jiang and Qiquan Quan \\ State Key Laboratory of Robotics and System, Harbin Institute of Technology, Harbin 15001, China; \\ kfr516258384@126.com (F.K.); dengzq@hit.edu.cn (Z.D.); jiangshy@hit.edu.cn (S.J.); \\ quanqiquan@hit.eud.cn (Q.Q.) \\ * Correspondence: dwtang@hit.edu.cn (D.T.); NumBer13_xh@163.com (H.X.); Tel.: +86-451-8641-8082 (H.X.) \\ Academic Editor: Chunhua Liu \\ Received: 13 February 2017; Accepted: 9 March 2017; Published: 13 March 2017
}

\begin{abstract}
The main task of the third Chinese lunar exploration project is to obtain soil samples that are greater than two meters in length and to acquire bedding information from the surface of the moon. The driving component is the power output unit of the drilling system in the lander; it provides drilling power for core drilling tools. High temperatures can cause the sensors, permanent magnet, gears, and bearings to suffer irreversible damage. In this paper, a thermal analysis model for this driving component, based on the thermal network method (TNM) was established and the model was solved using the quasi-Newton method. A vacuum test platform was built and an experimental verification method (EVM) was applied to measure the surface temperature of the driving component. Then, the TNM was optimized, based on the principle of heat distribution. Through comparative analyses, the reasonableness of the TNM is validated. Finally, the static temperature field of the driving component was predicted and the "safe working times" of every mode are given.
\end{abstract}

Keywords: lunar sampling; rotary motor; planetary reducer; thermal analysis; thermal network method (TNM); experimental verification

\section{Introduction}

There are many differences between the atmospheric environment of earth and celestial bodies [1-3]. For example, there is no air on the moon and the temperature of the environment reaches $127^{\circ} \mathrm{C}$ in the daytime, and $-183^{\circ} \mathrm{C}$ at night. The atmospheric pressure is lower than $10^{-10} \mathrm{~Pa}$. The gravitational acceleration of the lunar surface is about $1 / 6$ of the acceleration of the Earth's surface. A large amount of dust is suspended on the surface, which is a primary requirement for the seal design of the system. The main task of the third Chinese lunar exploration project is to obtain soil samples that are greater than two meters long, and to keep the bedding information from the surface of the moon. Due to meteorite impact, there are friable soils and high compactness soils. Furthermore, there is basalt on the moon. In the process of drilling, the working load is different depending on the drilling objects.

The driving component is the power output unit of the drilling system in the lander, and it consists of a rotary motor and planetary reducer. The temperature will rise at a rapid rate when the unit works on the moon. With respect to the rotary motor, the high temperature may cause the lifetime of the Holzer sensor (Zhong Xu, Nanjing, China) to decrease, resulting in burn-out and permanent magnet demagnetization. With respect to the planetary reducer, the elevated temperatures may cause a lubrication failure and decrease gear strength. In order to ensure that the system can work reliably, thermal analyses and experimental verification of the driving component should be conducted. 
Many studies on the temperature field are based on the thermal network method (TNM). Huang et al. [4] calculated the core loss accurately, and modeled the thermal behavior of the soft magnetic composite using two methods. The calculation and measurement results were compared and discussed. Guo et al. [5] presented a hybrid thermal model which was applied to calculate the temperature distributions in a claw pole permanent-magnet motor with a soft magnetic composite stator. Qiu et al. [6] studied the transient-state and steady-state temperature characteristics of a stator winding under constant and step-cycle patterns of wind speed. Wang et al. [7] established the stator temperature model of the high-power density asynchronous motor, and the model was solved using the Gauss-Seidel iteration. Long et al. [8] established a model of high-speed meshing gears, and the heat source of the meshing process was acquired. Changenet et al. [9] established a model that can predict the power loss of a six-speed manual gearbox, and the inner temperature of the gearbox was solved using the TNM. Liu et al. [10] studied the spindle system and built a model for thermal resistance, power loss, and convective heat transfer; the static temperature of the spindle system was then acquired. Chen et al. [11] combined the quasi-statics and heat-generating analyses of the bearing, and the heat source of the bearing was acquired. On the basis of thermal structure interaction, Yan et al. [12] developed a TNM for transient analysis.

The experimental verification of temperature field is as follows: Kim et al. [13] developed two cooling designs for the integrated starter generator motor and inverter, and then carried out an experiment on the fluid flow and thermal characteristics of the system. Chai et al. [14] used an outer-rotor air-cooling in-wheel motor as an example, the temperature field of the motor was calculated numerically and the results are experimentally verified. Song et al. [15] conducted a test on the water-cooled motor. Ma et al. [16] studied the ZD-10 transmission system, a moderate number of experiments were carried out, and the calculated results and limited test results were in good agreement. Talbot et al. [17] set up an experiment which included a specialized test apparatus to operate a planetary gear set under tightly-controlled speed, load, and oil temperature conditions, and instrumentation for an accurate measurement of power losses. De Gevigney [18] developed an FZG test platform, and a back-to-back gear test was performed on the platform. Yang et al. [19] studied the H7014C/HQ1 bearing. According to the tests on changing the speed, preload, and amount of lubricant, the conclusion that speed was the most significant effect was determined.

Much of the research above was conducted in the environments of Earth, and there is a lack of research on the study of celestial bodies. The driving component is a closed structure, and its shell is fixed. The inner parts rotate around the axis; the inner temperature cannot be directly tested. In this paper, a thermal analysis model of driving component is established using the TNM the temperature rise equations of every node are listed, based on the law of energy conservation. The quasi-Newton method is used to solve the equations, and the inner temperature of the working process is acquired. A vacuum box is used in order to establish a test platform to test the surface temperature of the driving component under different working modes.

\section{Structure of the Driving Component and Heat Source Analyses}

\subsection{Structure of the Driving Component}

The driving component is the power output unit of the drilling system in the lander. Rotary power is transmitted to the drilling tools using an intermediate system. The driving component includes a rotary motor and planetary reducer, as shown in Figure 1.

The rotary motor is a permanent-magnet, brushless DC motor. It uses a radial magnetic circuit structure, and the Holzer sensor is used as a position sensor. The planetary reducer includes a double $2 \mathrm{~K}-\mathrm{H}$ gear structure; the ratio of the reducer is 16:1, and the high-speed and low-speed levels have the same structure. The output power of the motor is directly used as the input power of the reducer. Solid lubrication is used in the driving component. Diamond-like carbon is sputtered onto the surface 
of the gears, and $\mathrm{MoS}_{2}$ is sputtered on the grooves of the bearing. The major parameters of the rotary motor and planetary reducer are tabulated in Table 1.

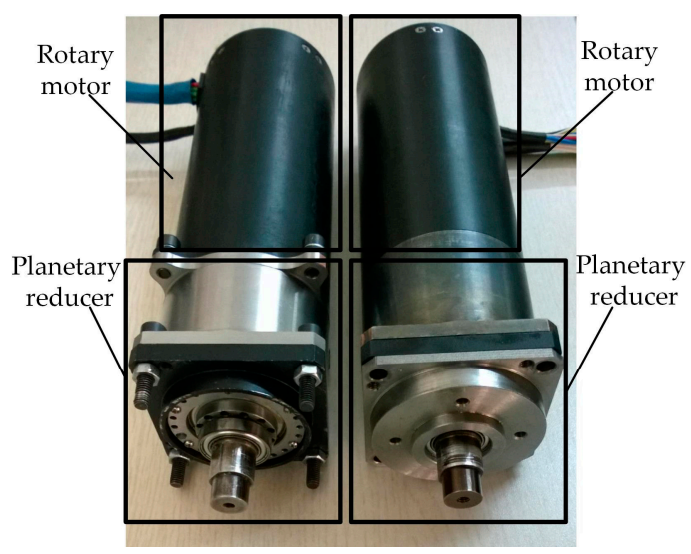

Figure 1. The driving component.

Table 1. The major parameters of the rotary motor and planetary reducer.

\begin{tabular}{|c|c|c|c|}
\hline $\begin{array}{l}\text { Parameter and } \\
\text { Dimension }\end{array}$ & Value & Parameter and Dimension & Value \\
\hline \multicolumn{2}{|c|}{ Rotary Motor } & \multicolumn{2}{|l|}{ Planetary Reducer } \\
\hline Number of phases & 3 & $\begin{array}{l}\text { Sun gear teeth number of } \\
\text { high-speed level }\end{array}$ & 18 \\
\hline Rated power & $1500 \mathrm{~W}$ & $\begin{array}{c}\text { Planetary gear teeth number of } \\
\text { high-speed level }\end{array}$ & 18 \\
\hline Rated speed & $7860 \mathrm{rpm}$ & $\begin{array}{l}\text { Ring gear teeth number of } \\
\text { high-speed level }\end{array}$ & 54 \\
\hline Number of poles & 6 & $\begin{array}{l}\text { Sun gear teeth number of } \\
\text { low-speed level }\end{array}$ & 18 \\
\hline Stator core material & $\begin{array}{l}\text { 20WTG1500 (Baowu, } \\
\text { Wuhan, China) }\end{array}$ & $\begin{array}{c}\text { Planetary gear teeth number of } \\
\text { low-speed level }\end{array}$ & 18 \\
\hline Stator outer diameter & $56 \mathrm{~mm}$ & $\begin{array}{l}\text { Ring gear teeth number of } \\
\text { low-speed level }\end{array}$ & 54 \\
\hline Stator inner diameter & $26 \mathrm{~mm}$ & Gear modulus & 1 \\
\hline Stator length & $100 \mathrm{~mm}$ & Gear pressure angle & $20^{\circ}$ \\
\hline Rotor core material & $45 \#$ steel & Transmission ratio of each level & $4: 1$ \\
\hline Outer diameter & $60 \mathrm{~mm}$ & Transmission ratio & $16: 1$ \\
\hline Permanent magnets & $\begin{array}{l}\text { XGS223/160 (XETC, } \\
\text { Chengdu, China) }\end{array}$ & Addendum coefficient & 1 \\
\hline Airgap length & $1.3 \mathrm{~mm}$ & Clearance coefficient & 0.25 \\
\hline Active axial length & $140 \mathrm{~mm}$ & - & - \\
\hline
\end{tabular}

\subsection{Heat Source Analyses of the Rotary Motor}

The heat source in the motor includes stator iron loss, winding copper loss, and mechanical loss.

\subsubsection{Analyses of Iron Loss}

According to the working principle of the motor, iron loss can be divided into hysteresis loss, eddy current loss, and additional loss. Iron loss can be expressed as:

$$
P_{F e}=P_{h}+P_{e}+P_{e x}
$$

where $P_{F e}$ is the iron loss $(\mathrm{W}), P_{h}$ is the hysteresis loss $(\mathrm{W}), P_{e}$ is the eddy current loss $(\mathrm{W}), P_{e x}$ is the additional loss $(\mathrm{W})$.

Unit mass of the iron loss can be expressed as:

$$
P_{F e}=K_{h} f B_{m}^{2}+K_{e} f^{2} B_{m}^{2}+K_{e x} f^{1.5} B_{m}^{1.5}
$$


where $K_{h}$ is the hysteresis loss coefficient, $K_{e}$ is the eddy current loss coefficient, $k_{e x}$ is the additional loss coefficient, $f$ is the frequency $(\mathrm{Hz})$, and $B_{m}$ is the maximum magnetic flux density $(\mathrm{T})$.

When the motor works in a normal magnetic flux density range $\left(1 \mathrm{~T}<B_{m}<1.8 \mathrm{~T}\right)$, the iron loss can be expressed as:

$$
P_{F e}=C_{F e} f^{1.3} B_{m}^{2} G
$$

where $C_{F e}$ is the iron loss coefficient, $G$ is the weight of the core $(\mathrm{kg})$.

\subsubsection{Analyses of Copper Loss}

According to the Joul-Lenzs laws, copper loss is equal to the product of the resistance and the square of the current. Copper loss can be expressed as:

$$
P_{C u}=2 I^{2} R_{C u}
$$

where $P_{C u}$ is the additional loss $(\mathrm{W}), R_{C u}$ is the resistance of each phase of the motor at the current temperature $(\Omega)$, and $I$ is the average phase current in a motor working cycle (A).

\subsubsection{Analyses of Mechanical Loss}

The mechanical loss contains windage loss and bearing loss. Due to the vacuum state on the moon, windage loss can be neglected, and only bearing loss is considered. The local method was used to calculate bearing heat. Bearing heat mainly includes sliding heat between the ball and raceway, gyroscope rotational heat, spin heat, sliding heat between the cage and ring, and the sliding friction heat of the cage.

$$
H_{t}=\sum_{j=1}^{j}\left(H_{1 m j}+H_{2 m j}+H_{m s j}+H_{c j}\right)+H_{C L}
$$

where $H_{t}$ is the bearing heat $(\mathrm{W}), H_{1 m j}$ is the sliding heat between the ball and raceway $(\mathrm{W}), H_{2 m j}$ is the gyroscope rotational heat $(\mathrm{W}), H_{m s j}$ is the spin heat $(\mathrm{W}), H_{c j}$ is the sliding heat between the cage and ring $(\mathrm{W})$, and $H_{C L}$ is the sliding friction heat of the cage $(\mathrm{W})$.

\subsection{Heat Source Analyses of the Planetary Reducer}

Frictional power loss can be caused by the process of gear meshing. For a contact area $(C)$, the heat flux generated by the frictional sliding of meshing teeth can be expressed as:

$$
\begin{gathered}
q_{1 c}=\beta q_{c}=\beta \eta \mu_{c} p_{N c} v_{g c} \times 10^{6} \\
q_{2 c}=(1-\beta) q_{c}=(1-\beta) \eta \mu_{c} p_{N c} v_{g c} \times 10^{6}
\end{gathered}
$$

where $q_{1 c}$ is the frictional heat flux density of a driving gear $\left(\mathrm{W} / \mathrm{m}^{2}\right), q_{2 c}$ is the frictional heat flux density of a driven gear $\left(\mathrm{W} / \mathrm{m}^{2}\right), \beta$ is the coefficient of friction heat flow distribution, $\eta$ is the coefficient of friction power loss turning into thermal energy, $\mu_{c}$ is the friction coefficient of a mesh surface, $p_{N c}$ is the contact pressure of mesh surface $(\mathrm{Pa})$, and $v_{g c}$ is the relative speed of the driving gear and driven gear $(\mathrm{m} / \mathrm{s})$.

\section{Thermal Analyses of the Driving Component Based on the Thermal Network Method}

\subsection{The Basic Principle of the Thermal Network Method}

The TNM is a thermoelectric analogy. Based on the law of energy conservation, the TNM is used in order to segment the driving component into nodes, between which thermal resistances exist. The heat flowing into the node equals the heat flowing out of the node and the heat that makes the node temperature rise. 


\subsubsection{The Principle of the Static Temperature Rise Analyses}

For the static state temperature field, the thermal model is segmented into $n$ nodes using the TNM. The heat flowing into the node equals the heat flowing out of the node. The static state equilibrium equations of the $n$-node system are expressed as:

$$
\left.\begin{array}{c}
Q_{1}=Q_{1}\left(T_{1}, T_{2}, \ldots, T_{n}\right)=0 \\
Q_{2}=Q_{2}\left(T_{1}, T_{2}, \ldots, T_{n}\right)=0 \\
\ldots \\
Q_{n}=Q_{n}\left(T_{1}, T_{2}, \ldots, T_{n}\right)=0
\end{array}\right\}
$$

where $Q_{1}, Q_{2}, \ldots, Q_{n}$ is the heat which makes the temperature of the node 1 , the node $2, \ldots$, the node $n$ rise $(\mathrm{W}), T_{1}, T_{2}, \ldots, T_{n}$ is the static temperature of the node 1 , the node $2, \ldots$, the node $n(\mathrm{~K})$, and $n$ is the number of the nodes.

\subsubsection{The Principle of Transient Temperature Rise Analyses}

With respect to the transient state temperature field, the heat flowing into the node equals the heat flowing out and also the heat that causes the temperature of the node to rise. The transient state equilibrium equation of the $n$-node system is expressed as:

$$
\rho_{i} c_{p i} V_{i} \frac{\mathrm{d} T_{i}}{\mathrm{~d} t}=Q_{i}(i=1,2, \ldots, n)
$$

where $i$ is the node number, $\rho_{i}$ is the density of node $i\left(\mathrm{~kg} / \mathrm{m}^{3}\right), c_{p i}$ is the specific heat of node $i$ $(\mathrm{J} /(\mathrm{kg} \cdot \mathrm{K})), V_{i}$ is the volume of node $i\left(\mathrm{~m}^{3}\right)$, and $Q_{i}$ is the difference of heat flowing into the node and heat flowing out of the node $(\mathrm{W})$.

\subsection{Thermal Resistance}

Three categories of thermal resistance are considered.

\subsubsection{Conduction Resistance}

When the study object is a plane, the conduction resistance can be expressed as:

$$
R_{w}=\frac{L_{w}}{\lambda A_{w}}
$$

where $R_{w}$ is the conduction resistance of a plane $(\mathrm{K} / \mathrm{W}), L_{w}$ is the object length of heat transfer direction $(\mathrm{m}), \lambda$ is the conductivity of the material $(\mathrm{W} /(\mathrm{m} \cdot \mathrm{K})), A_{w}$ is the wall surface area in vertical direction of heat transfer $\left(\mathrm{m}^{2}\right)$.

The conduction resistance of a cylindrical surface can be expressed as:

$$
R_{c}=\frac{\ln \left(r_{o} / r_{i}\right)}{2 \pi L_{c} \lambda}
$$

where $R_{c}$ is the conduction resistance of a cylindrical surface $(\mathrm{K} / \mathrm{W}), r_{i}$ and $r_{o}$ are the radius of the cylindrical inner wall and outer wall $(\mathrm{m})$, and $L_{c}$ is the axial length perpendicular to the direction of heat flow $(m)$.

\subsubsection{Contact Resistance}

Contact resistance and the contact heat transfer coefficient can be expressed as:

$$
\begin{gathered}
R_{c t}=\frac{1}{h_{c} A_{c t}} \\
h_{c}=\frac{1}{L_{g}} \frac{A_{c t}^{c}}{A_{c t}} \frac{2 \lambda_{A} \lambda_{B}}{\lambda_{A}+\lambda_{B}}
\end{gathered}
$$


where $R_{c t}$ is the contact resistance $(\mathrm{K} / \mathrm{W}), h_{c}$ is the contact heat transfer coefficient $\left(\mathrm{W} /\left(\mathrm{m}^{2} \cdot \mathrm{K}\right)\right), A_{c t}$ is the nominal contact area $\left(\mathrm{m}^{2}\right), A_{c t}^{c}$ is the actual contact area $\left(\mathrm{m}^{2}\right), L_{g}$ is the thickness of the gap between contact surfaces $(\mathrm{m})$.

\subsubsection{Radiation Resistance}

Under ideal conditions, the radiation resistance of a grey body can be expressed as:

$$
R_{r}=\frac{1}{\varepsilon A_{r} \sigma\left(T_{1}+T_{0}\right)\left(T_{1}^{2}+T_{0}^{2}\right)}
$$

where $A_{r}$ is the area of radiation surface $\left(\mathrm{m}^{2}\right), T_{1}$ is the thermodynamic temperature $(\mathrm{K}), T_{0}$ is the thermodynamic temperature of environment $(\mathrm{K}), \sigma$ is the radiation constant of blackbody $\left(\mathrm{W} /\left(\mathrm{m}^{2} \cdot \mathrm{K}^{4}\right)\right)$, and $\varepsilon$ is the emissivity.

\subsection{Node Partition and the Model of the Driving Component}

The driving component is divided into 100 nodes, of which 54 nodes constitute the structure of the motor and 46 nodes constitute the structure of the reducer. Node partition of the driving component is shown in Figure 2.

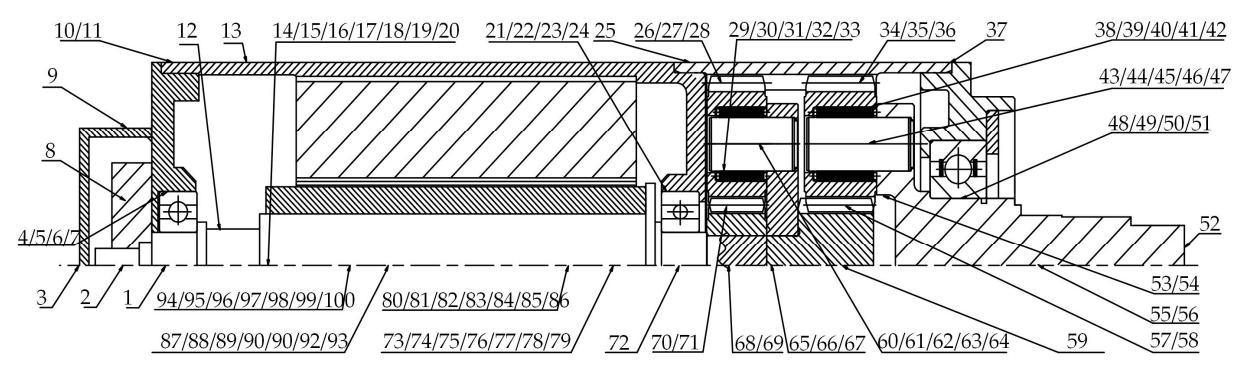

Figure 2. Node partition of the driving component.

The serial numbers and definitions of all nodes are shown in Table 2.

Table 2. Serial numbers and definitions of every node.

\begin{tabular}{|c|c|c|c|c|c|}
\hline \multirow{2}{*}{$\begin{array}{l}\text { Serial } \\
\text { Number }\end{array}$} & \multirow{2}{*}{ Definition } & \multirow{2}{*}{ Value } & \multirow{2}{*}{$\begin{array}{c}\text { Conductivity } \\
(\mathrm{W} / \mathrm{m} \cdot \mathrm{K})\end{array}$} & \multirow{2}{*}{$\begin{array}{c}\text { Specific Heat } \\
(\mathrm{J} / \mathrm{kg} \cdot \mathrm{K})\end{array}$} & \multirow{2}{*}{$\begin{array}{l}\text { Density } \\
\left(\mathrm{kg} / \mathrm{m}^{3}\right)\end{array}$} \\
\hline & & & & & \\
\hline 1 & Average temperature of the end axis of the motor near bearing & $T_{1}$ & 45 & 490 & 7800 \\
\hline 2 & Average temperature of the axis near the hall sensor & $T_{2}$ & 45 & 490 & 7800 \\
\hline 3 & Average temperature of the end surface & $T_{3}$ & 126 & 871 & 2660 \\
\hline 4 & $\begin{array}{l}\text { Average temperature of the contact area of the axis and the } \\
\text { inner ring of the bearing }\end{array}$ & $T_{4}$ & 45 & 490 & 7800 \\
\hline 5 & $\begin{array}{l}\text { Average temperature of the contact area of the inner ring and } \\
\text { the ball }\end{array}$ & $T_{5}$ & 38.2 & 492 & 7822 \\
\hline 6 & $\begin{array}{l}\text { Average temperature of the contact area of the outer ring and } \\
\text { the ball }\end{array}$ & $T_{6}$ & 38.2 & 492 & 7822 \\
\hline 7 & $\begin{array}{l}\text { Average temperature of the contact area of the end cover and } \\
\text { the outer ring }\end{array}$ & $T_{7}$ & 38.2 & 492 & 7822 \\
\hline$\ldots$ & $\ldots$ & $\ldots$ & $\ldots$ & $\ldots$ & $\ldots$ \\
\hline 97 & $\begin{array}{l}\text { Average temperature of the stator tooth of the front part of } \\
\text { the motor }\end{array}$ & $T_{97}$ & 2.7 & 415.7 & 8200 \\
\hline 98 & $\begin{array}{l}\text { Average temperature of the stator yoke of the front part of } \\
\text { the motor }\end{array}$ & $T_{98}$ & 40 & 480 & 7700 \\
\hline 99 & $\begin{array}{l}\text { Average temperature of the stator surface of the front part of } \\
\text { the motor }\end{array}$ & $T_{99}$ & 40 & 480 & 7700 \\
\hline 100 & $\begin{array}{l}\text { Average temperature of the shell surface of the front part of } \\
\text { the motor }\end{array}$ & $T_{100}$ & 126 & 871 & 2660 \\
\hline
\end{tabular}


According to the node partition, the thermal network model of the driving component is shown in Figure 3.

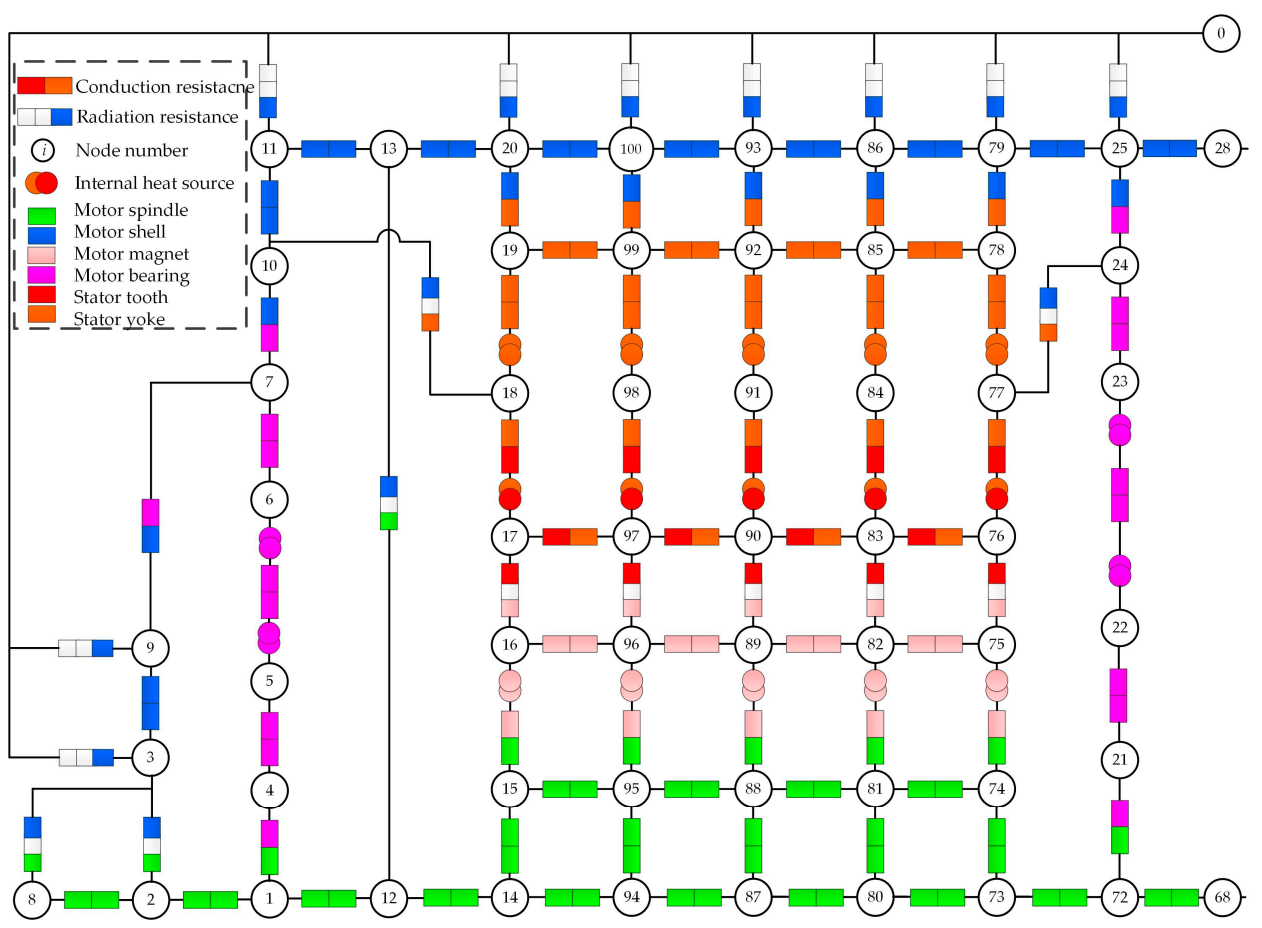

(a)

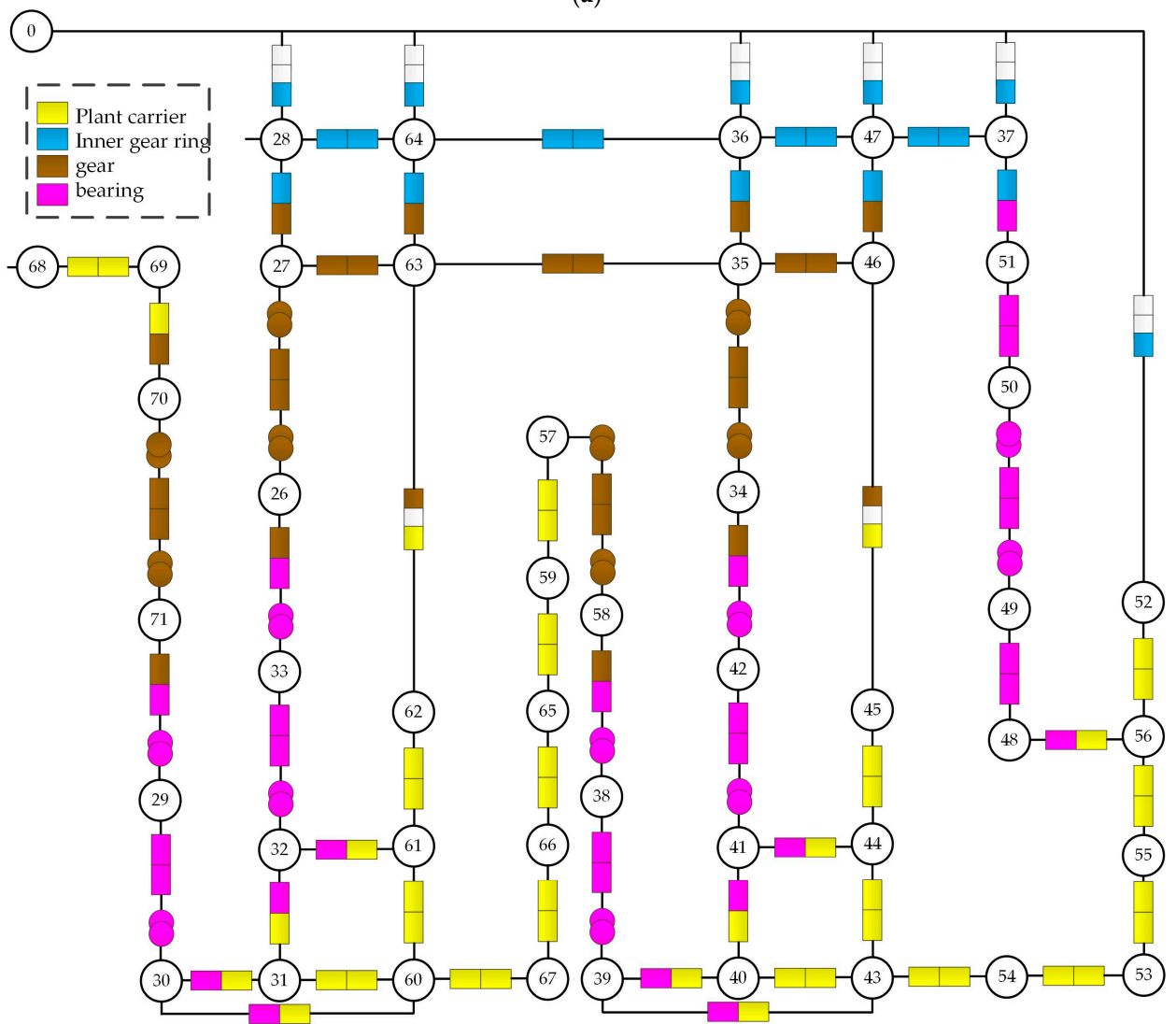

(b)

Figure 3. Thermal model of the driving component: (a) the thermal model of the motor and; (b) the thermal model of the reducer. 


\subsection{Solution of the Temperature Rise Equations}

The working time of the driving component on the moon is less than $2 \mathrm{~h}$; the inner temperature cannot reach an equilibrium state in an environment with no convection. In this paper, mainly the transient temperature field is studied. The transient heat equation of every node can be expressed as:

$$
Q=\left[\rho_{i} C_{p i} V_{i}\right]\left[\frac{\Delta T}{\Delta \tau}\right]+\left[\frac{1}{R_{i j}}\right]\left[T_{i}\right]
$$

The transient heat equations of the driving component can be expressed as:

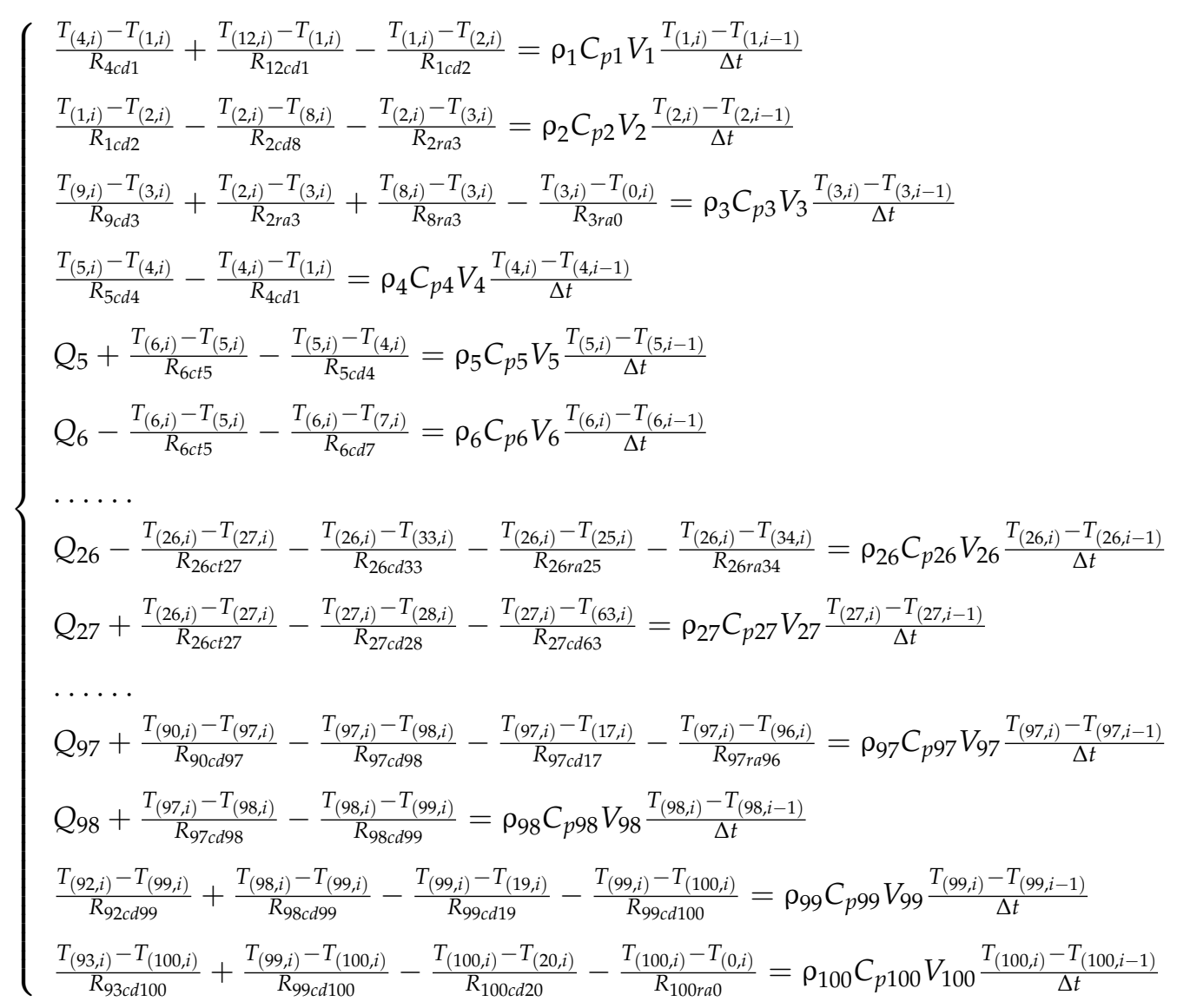

Equation (16) is a multiple high-order non-linear equation; the quasi-Newton method is used in order to solve the equation. The general form of the system equations can be expressed as:

$$
F(x)=0, F(x)=\left(f_{1}, f_{2}, \ldots, f_{n}\right)^{T}, x=\left(x_{1}, x_{2}, \ldots, x_{n}\right)^{T}
$$

The quasi-Newton method for solving the equations of the general formula (Equation (17)) can be expressed as:

$$
\begin{gathered}
x^{i+1}=x^{i}-A_{i}^{-1} F\left(x^{i}\right), i=0,1, \cdots, n \\
A_{i}=F^{\prime}\left(x^{i}\right)=\left[\begin{array}{cccc}
\frac{\partial f_{1}}{\partial x_{1}^{i}} & \frac{\partial f_{1}}{\partial x_{2}^{i}} & \cdots & \frac{\partial f_{1}}{\partial x_{n}^{i}} \\
\frac{\partial f_{2}}{\partial x_{1}^{i}} & \frac{\partial f_{2}}{\partial x_{2}^{i}} & \cdots & \frac{\partial f_{2}}{\partial x_{n}^{i}} \\
\vdots & \vdots & & \vdots \\
\frac{\partial f_{n}}{\partial x_{1}^{i}} & \frac{\partial f_{n}}{\partial x_{2}^{i}} & \cdots & \frac{\partial f_{n}}{\partial x_{n}^{i}}
\end{array}\right] \in R^{n \times n}
\end{gathered}
$$


Calculation of the internal temperature field of the driving component is realized using MATLAB (version R2010a, https:/ / www.mathworks.com/); the relationships between the modules are shown in Figure 4.

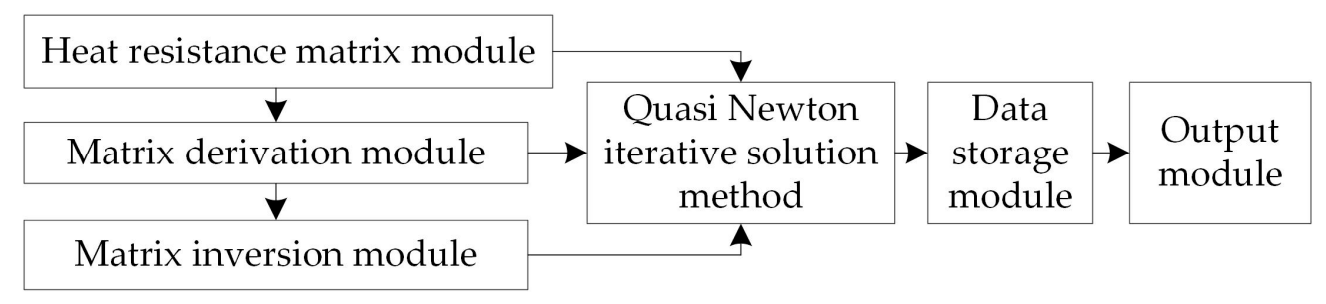

Figure 4. Module relationships in MATLAB.

The temperature field can be acquired when the parameters of the driving component are written into the program. The solving procedure is shown in Figure 5.

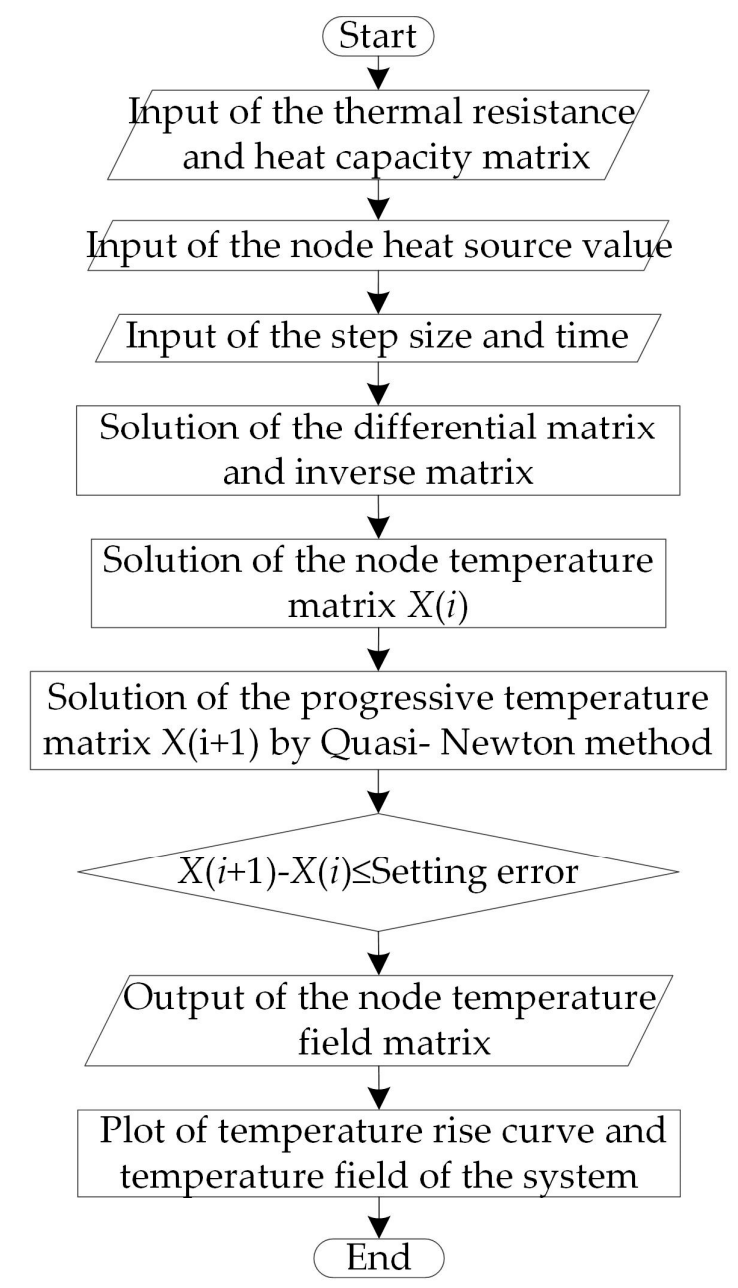

Figure 5. Solving procedure of the temperature field. 


\subsection{Results and Analyses}

When the environmental temperature is $80^{\circ} \mathrm{C}$, the working speed is $300 \mathrm{rpm}$ and the working load is $6 \mathrm{Nm}\left(80^{\circ} \mathrm{C}-300 \mathrm{rpm}-6 \mathrm{Nm}\right.$ for short); the power loss of the motor and reducer is shown in Table 3, and the inner temperature field after $10 \mathrm{~min}$ is shown in Figure 6.

Table 3. Power loss of the motor and reducer.

\begin{tabular}{ccccc}
\hline Location & Iron Loss & Copper Loss & Gear Meshing Loss & Bearing Loss \\
\hline Heat source $(\mathrm{W})$ & 14.5461 & 3.8789 & 12.1994 & 1.3352 \\
\hline
\end{tabular}

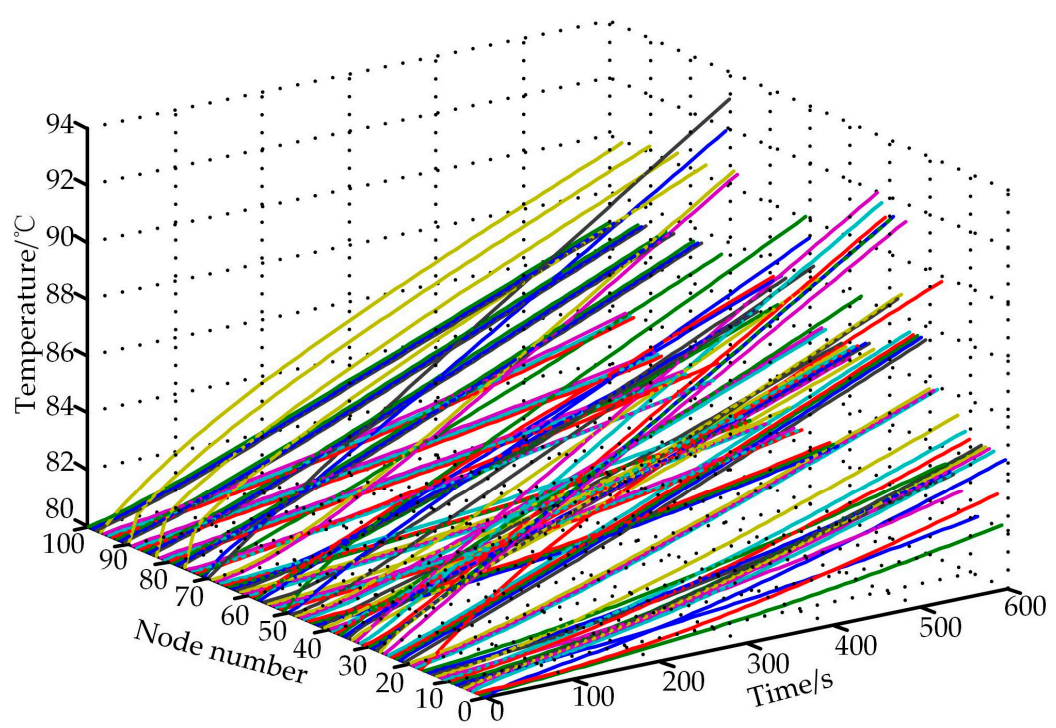

Figure 6. Inner temperature field after $10 \mathrm{~min}$.

In Figure 6, the temperature of node 76 of the stator tooth is the highest in the motor $\left(90.1^{\circ} \mathrm{C}\right)$. In the reducer, the highest temperature occurs at the location of node $70\left(93.1^{\circ} \mathrm{C}\right)$.

\section{Experimental Verification}

The surface environment of the moon is very different from that of Earth. Two factors that affect the temperature increase the most are the environmental temperature and the high vacuum state. On the moon, the atmospheric pressure is below $10^{-10} \mathrm{~Pa}$; in order to reduce the influence of the extreme environmental temperature, a protection shield is mounted on the outside of the drilling system, which can maintain the environmental temperature of the drilling system between $-40{ }^{\circ} \mathrm{C}$ and $80^{\circ} \mathrm{C}$. In the ground simulation experiment, ambient temperature and atmospheric pressure are the two main aspects that are simulated.

\subsection{Overview of the Vacuum Test Platform}

The vacuum test platform was established based on the vacuum chamber. The inside of the vacuum chamber includes the driving component, couplings, and temperature-testing equipment, among other components. The outside of the vacuum chamber is composed of a photoelectric encoder, torque sensor, hysteresis brake, and other components. The vacuum platform is shown in Figure 7.

Eight Pt100 temperature sensors (XETC, Harbin, China) were used in the experiment in order to test the temperatures at different locations. Test point 1 to test point 6 are arranged from the front of the surface to the end surface, in turn, on the driving component. Test point 7 and test point 8 are located on the surface of the stator tooth and stator yoke, respectively. The locations of test sensors are shown in Figure 8. 


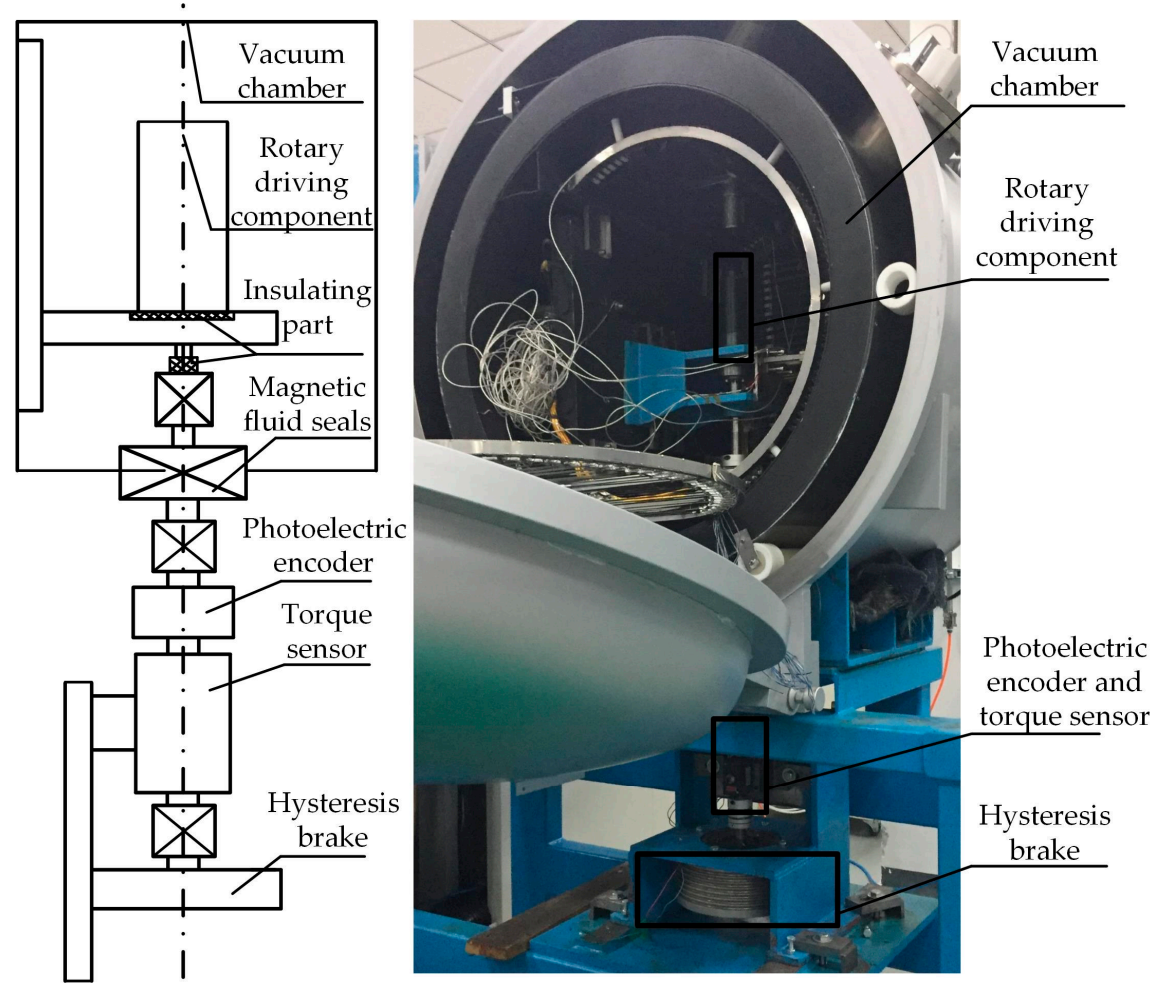

Figure 7. Vacuum test platform.

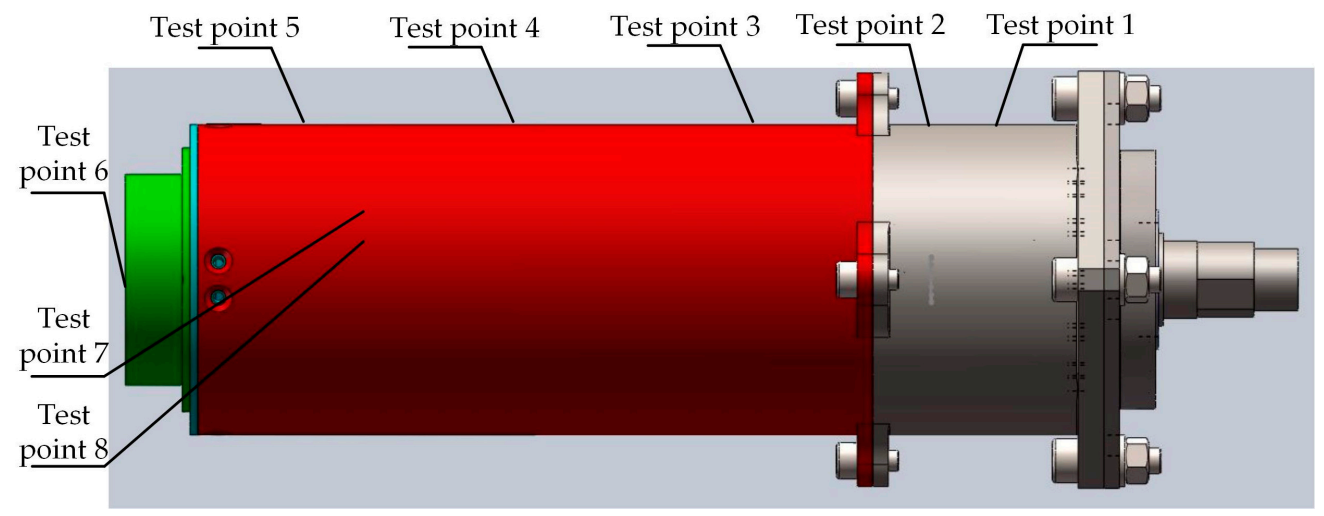

Figure 8. The locations of every test sensor.

\subsection{Test of the Transmission Resisting Torque}

In the test system shown in Figure 7, there is transmission-resisting torque because of the influence of the coaxial degree. The working torque consists of the transmission-resisting torque and the torque of the hysteresis brake:

$$
N=N_{t}+N_{h}
$$

where $N$ is the working torque $(\mathrm{Nm}), N_{t}$ is the transmission resisting torque $(\mathrm{Nm}), N_{h}$ is the torque of the hysteresis brake $(\mathrm{Nm})$.

Torque sensor $\mathrm{T}$ is mounted below the driving component (Figure 9). To make the system work under no load, the transmission-resisting torque at different working speeds can be acquired. The resisting torque is shown in Figure 10. 


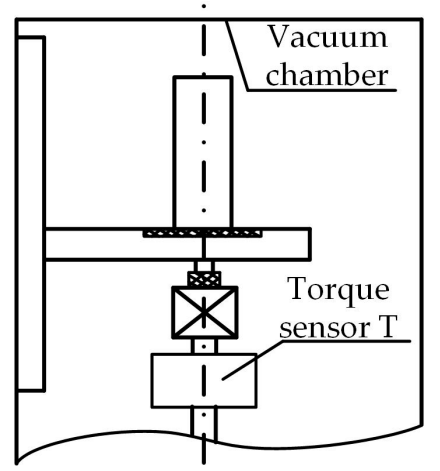

Figure 9. Location of sensor T.

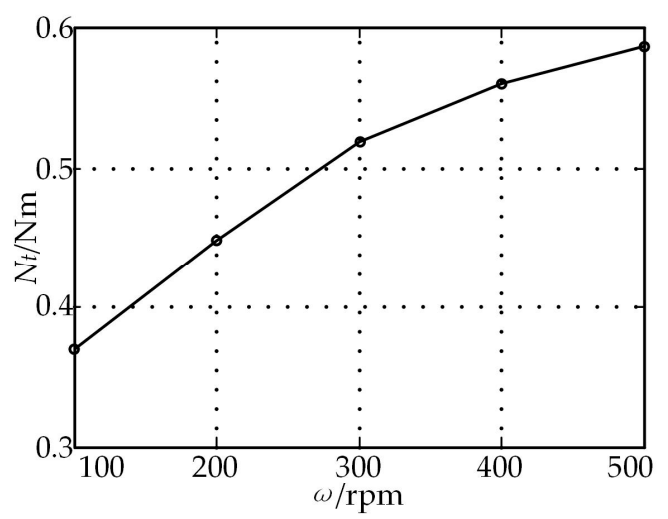

Figure 10. Transmission-resisting torque.

\subsection{Results of the Vacuum Tests}

Taking $80{ }^{\circ} \mathrm{C}-300 \mathrm{rpm}-6 \mathrm{Nm}$ as an example, the temperature of the test points after a 10 -min working time are shown in Figure 11.

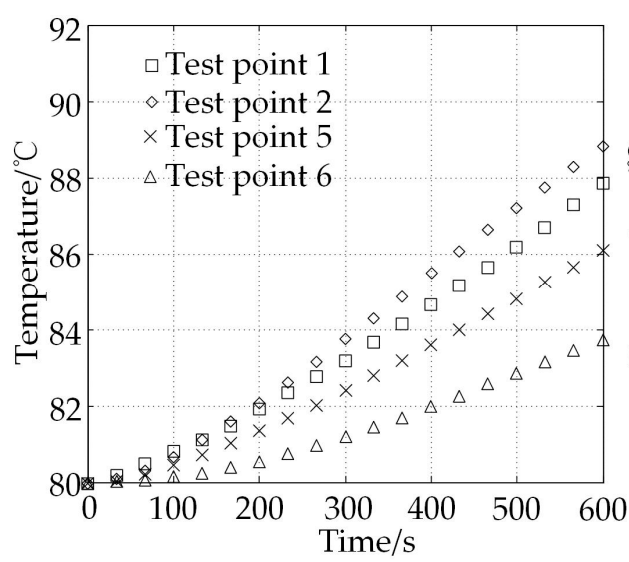

(a)

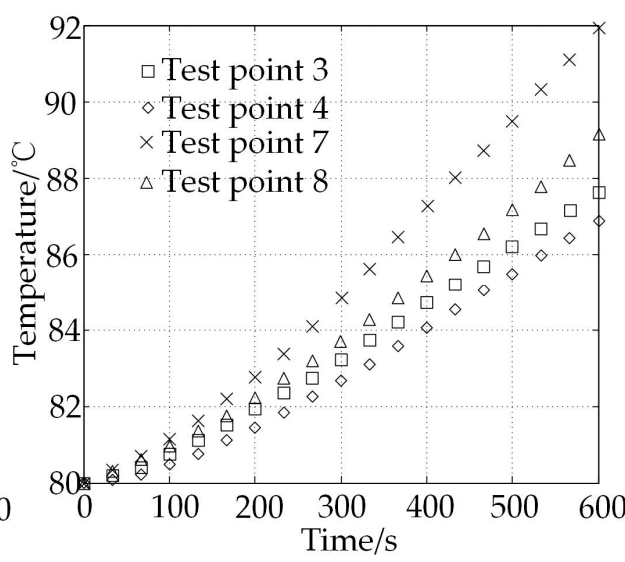

(b)

Figure 11. The test point temperatures of $80^{\circ} \mathrm{C}-300 \mathrm{rpm}-6 \mathrm{Nm}$ mode. (a) Temperature of point 1 , point 2, point 5 , and point 6 ; (b) Temperature of point 3 , point 4 , point 7 and point 8 .

According to the comparisons, there is an error between the theoretical results and the experimental results. For example, the theoretical temperature of test point 1 was $86.6{ }^{\circ} \mathrm{C}$, and the experimental result was $88.0^{\circ} \mathrm{C}$. The theoretical temperature of test point 2 was $87.7^{\circ} \mathrm{C}$, and 
the experimental result was $88.8^{\circ} \mathrm{C}$. The theoretical temperature of test 7 was $90.07{ }^{\circ} \mathrm{C}$, and the experimental result was $91.9^{\circ} \mathrm{C}$. In the theoretical analyses, there are assumptions in the model and the assumed parameters cannot be fully consistent with the actual parameters; thus, errors exist between the theoretical and experimental results.

\section{Thermal Network Optimization Method}

\subsection{Thermal Network Optimization Method Based on Heat Distribution}

In this section, the motor stator and gear meshing area, which are the main heat generating areas, will be explained.

In the motor thermal model above, there are three nodes in the stator tooth, stator yoke, and stator surface. In the optimization model, according to the change of radial loss density, the three areas are refined to be eight nodes, and the optimized model of the stator is shown in Figure 12.

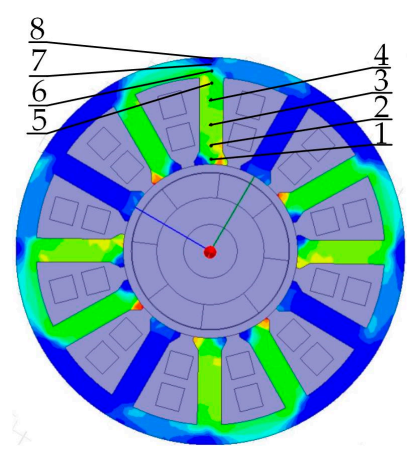

(a)

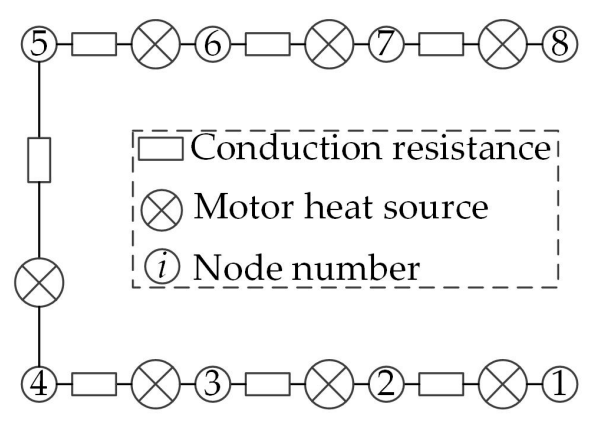

(b)

Figure 12. Optimization model of the motor stator. (a) Structure of the stator; (b) The refined thermal network model.

In the reducer thermal model above, there are four nodes in the model of the gear meshing tooth; they are node 1 to node 4 in the Figure 13a. In order to introduce the axial heat distribution and heat transfer process, node 2 and node 3 are refined in the axial direction. The optimized model of the gear meshing tooth is shown in Figure 13.

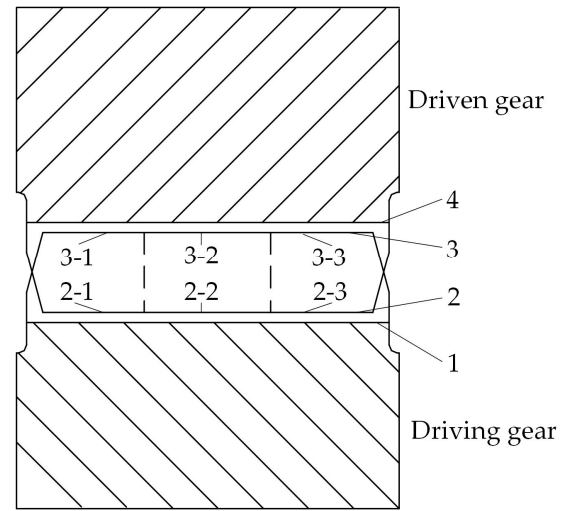

(a)

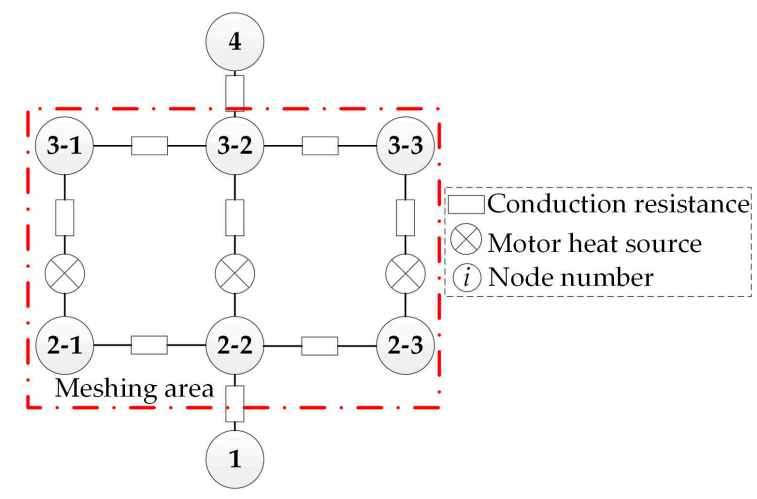

(b)

Figure 13. Optimization model of the reducer. (a) Gear meshing area; (b) The refined thermal network model. 


\subsection{Optimization Result Analyses}

The optimization model is solved using MATLAB. The node temperature of the $80{ }^{\circ} \mathrm{C}-300 \mathrm{rpm}-6$ Nm mode is shown in Figure 14.

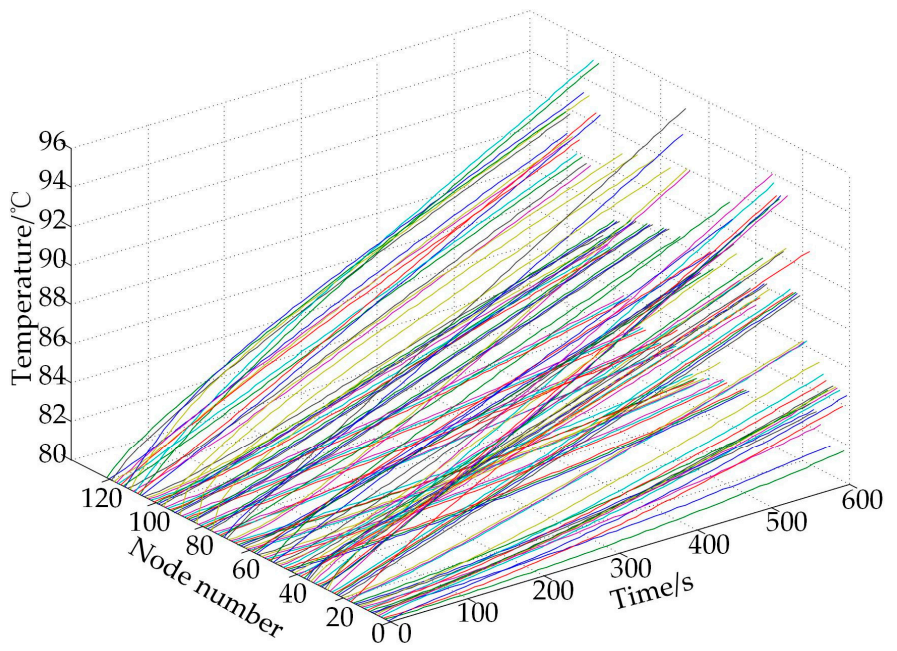

Figure 14. Node temperature of the $80^{\circ} \mathrm{C}-300 \mathrm{rpm}-6 \mathrm{Nm}$ mode.

After 10 min of working time, the theoretical temperature of test point 1 was $88.1^{\circ} \mathrm{C}$ and the experimental result was $88.0^{\circ} \mathrm{C}$. The theoretical temperature of test point 2 was $90.3^{\circ} \mathrm{C}$, and the experimental result was $88.8^{\circ} \mathrm{C}$. The theoretical temperature of test 7 was $92.0^{\circ} \mathrm{C}$, and the experimental result was $91.9^{\circ} \mathrm{C}$. The contrast curves of the eight test points are shown in Figure 15.

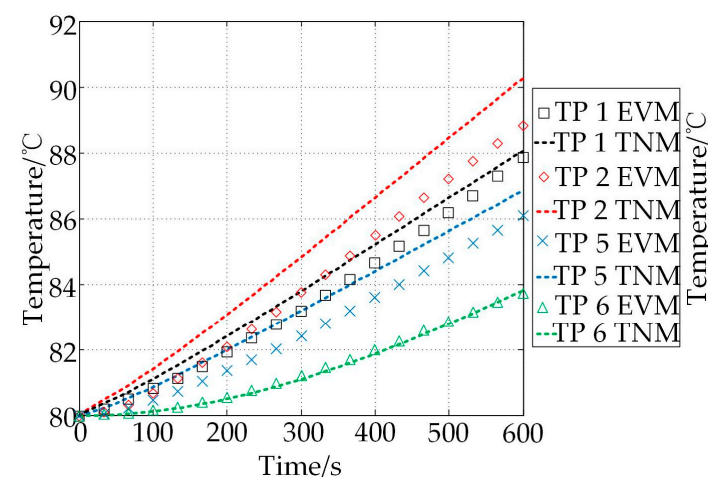

(a)

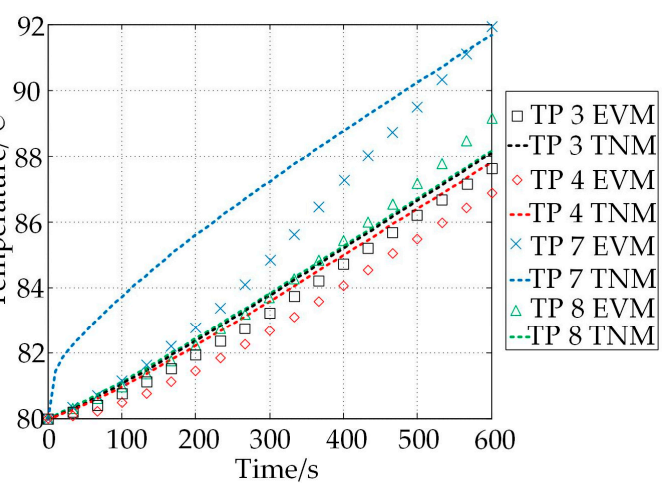

(b)

Figure 15. Comparison between the theoretical curves and the experimental curves. (a) Comparison curves of point 1 , point 2 , point 5 and point 6 ; (b) Comparison curves of point 3 , point 4 , point 7 and point 8.

In Figure 15, the error of test point 2 was the largest of all test points. The error of the theoretical and experimental results was $1.5^{\circ} \mathrm{C}$. With respect to the temperature rise trends, the theoretical trend of the first seven test points were the same as the actual trend. In the first $200 \mathrm{~s}$, the temperature increase was slow; however, it sped up after $200 \mathrm{~s}$, and the temperature rise trend presented a concave shape. However, the opposite trend occurs in the curve of the theoretical trend of test point 7 . In the early stage of working, the net heat flow of test point 7 is greatest because of the stator tooth in the heat-generating area. With the increase in temperature differences with other nodes, the net heat flow decreases and the temperature rise rate decreases. Thus, the theoretical temperature rise trend of test point 7 presents a convex shape. In the temperature-measurement process, the heat source temperature, measured using 
the test point, is indirect and is equivalent to increasing the heat conduction process in the conduction path. Meanwhile, because of the inner structure, the connection of the temperature sensor and the stator tooth is not very good; the test value lags behind the actual value, and the experimental curve of test point 7 presents a concave shape.

\subsection{Theoretical Prediction of the Static Temperature Field}

According to the differences in lunar soil compactness, the working modes of the driving component are very different. In this section, taking mode $A$ and mode $B$ as examples, the heat flow of each mode is acquired, based on working parameters. The parameters of mode A and mode B are shown in Table 4.

Table 4. The parameters of mode A and mode B.

\begin{tabular}{ccccc}
\hline Mode & Speed $(\mathbf{r p m})$ & Load $(\mathbf{N m})$ & Temperature $\left({ }^{\circ} \mathrm{C}\right)$ & Heat Flow $(\mathbf{W})$ \\
\hline A & 160 & 15 & 80 & 74.4 \\
B & 480 & 9 & 80 & 99.6 \\
\hline
\end{tabular}

With the increase in surface temperature, the radiation power will be equal to the heat-generating power when the system achieves equilibrium. According to the parameters of each mode, the theoretical prediction of the static temperature field are shown in Figure 16.

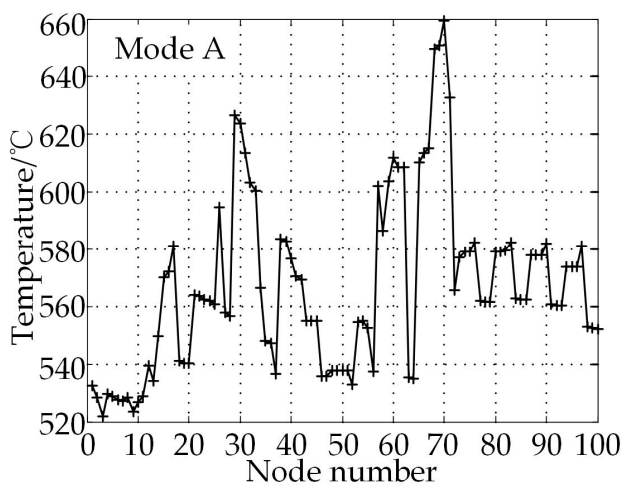

(a)

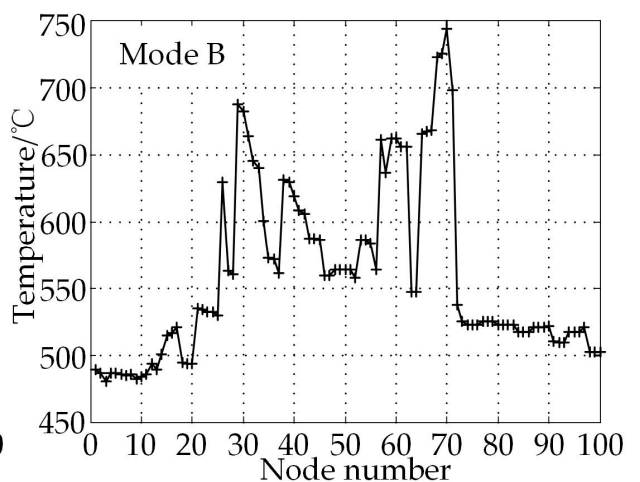

(b)

Figure 16. Static temperature field of mode A (a) and mode B (b).

In Figure 16, the inner node's temperature of the reducer is generally higher than that of the motor. In the lunar environment, the static temperature of the driving component is very high when the heat radiation is the only cooling method. The discontinuous working mode should be used in order to avoid damage due to the high temperature.

\subsection{The Prediction of Safe Working Times}

High temperature can cause irreversible damage to sensors, the permanent magnet, gears, and bearings. In this section, the TNM is used to predict safe working times in which the maximum temperature of the motor reaches $150{ }^{\circ} \mathrm{C}$. For modes $\mathrm{A}$ and $\mathrm{B}$, the temperature rise curves of the maximum-temperature node in the motor are shown in Figure 17. 


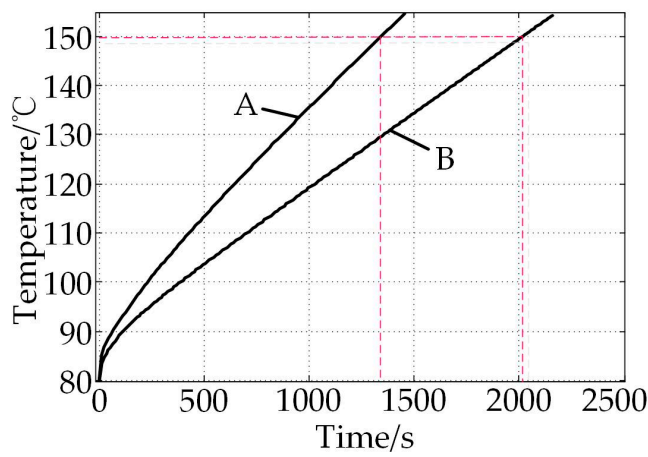

Figure 17. The temperature rise curves of the maximum-temperature node.

In Figure 17, the time that it takes the temperature to reach $150{ }^{\circ} \mathrm{C}$ is $1341.5 \mathrm{~s}$ in mode $\mathrm{A}$, and $2014.7 \mathrm{~s}$ in mode B.

\section{Conclusions}

(1) According to a comparison of the theoretical and experimental results, the results of the TNM are reasonable and the optimization method, based on heat distribution, is feasible.

(2) In the reducer, the energy was conducted from the input side to the output side, and from the sun gear to the ring. In the motor, the energy was conducted from the output side to the end, and from the stator to the axis and shell.

(3) The static temperature field of mode A and mode B were acquired, and the discontinuous working mode should be used in order to avoid damage due to the high temperatures. A safe working time, in which the maximum temperature $\left(150^{\circ} \mathrm{C}\right)$ in the motor was predicted, and the sampling task on the moon can be achieved safely and reliably.

Acknowledgments: This work was financially supported by the technology research projects of the China lunar exploration (Project Nos. TY3Q20110001 and TY3Q20110005), the National Nature Science Foundation of China (Grant Nos. 51105092 and 61403106), the 111 Project (Project No. B07018), and the International Science and Technology Cooperation Program of China (Project No. 2014DFR50250).

Author Contributions: Dewei Tang, Hong Xiao and Fanrui Kong organized the overall numerical analysis and experimental verification; Zongquan Deng, Shengyuan Jiang, and Qiquan Quan provided guidance and key suggestions.

Conflicts of Interest: The authors declare no conflict of interest.

\section{References}

1. Arkani-Hamed, J. The lunar mascons revisited. J. Geophys. Res. Planets 1998, 103, 3709-3739. [CrossRef]

2. Ouyang, Z. The progess of lunar exploration and Chinese lunar exploration project. Bull. Natl. Sci. Found. China 2003, 17, 193-197.

3. Zuber, M.T.; Smith, D.E.; Lemoine, F.G.; Neumann, G.A. The shape and internal structure of the Moon from the Clementine mission. Science 1994, 266, 1839-1843. [CrossRef] [PubMed]

4. Huang, Y.; Zhu, J.; Guo, Y. Thermal Analysis of High-Speed SMC Motor Based on Thermal Network and 3-D FEA with Rotational Core Loss Included. IEEE Trans. Magn. 2009, 45, 4680-4683. [CrossRef]

5. Guo, Y.; Zhu, J.G.; Wu, W. Thermal analysis of soft magnetic composite motors using a hybrid model with distributed heat sources. IEEE Trans. Magn. 2005, 41, 2124-2128.

6. Qiu, Y.; Zhang, W.; Cao, M.; Feng, Y.; Infield, D. An Electro-Thermal Analysis of a Variable-Speed Doubly-Fed Induction Generator in a Wind Turbine. Energies 2015, 8, 3386-3402. [CrossRef]

7. Wang, B.S.; Dou, M.F. Stator Temperature Calculation of High Power Density Asynchronous Motor Based on Thermal Network. Small Spec. Electr. Mach. 2006, 34, 24-26. 
8. Long, H.; Lord, A.A.; Gethin, D.T.; Roylance, B.J. Operating temperatures of oil-lubricated medium-speed gears: Numerical models and experimental results. Proc. Inst. Mech. Eng. G J. Aerosp. Eng. 2003, 217, 392-393. [CrossRef]

9. Changenet, C.; Oviedo-Marlot, X.; Velex, P. Power Loss Predictions in Geared Transmissions Using Thermal Networks-Applications to a Six-Speed Manual Gearbox. J. Mech. Des. 2006, 128, 618-625. [CrossRef]

10. Liu, C.; Luo, G.; He, W.; Hu, X. Steady state thermal analysis of a spindle system based on thermal network. Zhongguo Jixie Gongcheng/China Mech. Eng. 2010, 21, 631-635.

11. Chen, G.C.; Wang, L.Q.; Le, G.; Zheng, D.Z. Heating analysis of the high speed ball bearing. Hangkong Dongli Xuebao/J. Aerosp. Power 2007, 22, 163-168.

12. Yan, K.; Hong, J.; Zhang, J.; Mi, W.; Wu, W. Thermal-deformation coupling in thermal network for transient analysis of spindle-bearing system. Int. J. Therm. Sci. 2016, 104, 1-12. [CrossRef]

13. Kim, S.C. Thermal Performance of Motor and Inverter in an Integrated Starter Generator System for a Hybrid Electric Vehicle. Energies 2013, 6, 6102-6119. [CrossRef]

14. Chai, F.; Tang, Y.; Pei, Y.; Liang, P.; Gao, H. Temperature field accurate modeling and cooling performance evaluation of direct-drive outer-rotor air-cooling in-wheel motor. Energies 2016, 9, 818. [CrossRef]

15. Song, Q.; Wang, Z.F.; Zhang, C.N. Research of test method for winding temperature of electric vehicle driving motor. Small Spec. Electr. Mach. 2006, 34, 1-3.

16. Ma, X.; Li, J.; Chen, G. Experimentally supported stable thermal analysis of gearbox transmission system. J. Northwest. Polytech. Univ. 2002, 20, 32-35.

17. Talbot, D.C.; Kahraman, A.; Singh, A. An experimental investigation of the efficiency of planetary gear sets. J. Mech. Des. 2011, 120, 728-734.

18. De Gevigney, J.D.; Changenet, C.; Ville, F.; Velex, P. Thermal modelling of a back-to-back gearbox test machine: Application to the FZG test rig. Proc. Inst. Mech. Eng. Part J J. Eng. Tribol. 2012, 226, 501-515. [CrossRef]

19. Yang, H.L.; Zhang, Z.Q.; Yan, W. Thermal analysis and verification for high speed precision angular contact ball bearings. Bearing 2015, 4, 12-16.

(C) 2017 by the authors. Licensee MDPI, Basel, Switzerland. This article is an open access article distributed under the terms and conditions of the Creative Commons Attribution (CC BY) license (http:/ / creativecommons.org/licenses/by/4.0/). 